\title{
Effects of chronic manganese exposure on attention and working memory in non-human primates.
}

\author{
Jay S. Schneider \\ Thomas Jefferson University \\ Charles Williams \\ Thomas Jefferson University \\ Mark Ault \\ Thomas Jefferson University \\ Tomás R. Guilarte \\ Columbia University
}

Follow this and additional works at: https://jdc.jefferson.edu/pacbfp

Part of the Medicine and Health Sciences Commons

Let us know how access to this document benefits you

\section{Recommended Citation}

Schneider, Jay S.; Williams, Charles; Ault, Mark; and Guilarte, Tomás R., "Effects of chronic manganese exposure on attention and working memory in non-human primates." (2015). Department of Pathology, Anatomy, and Cell Biology Faculty Papers. Paper 190. https://jdc.jefferson.edu/pacbfp/190

This Article is brought to you for free and open access by the Jefferson Digital Commons. The Jefferson Digital Commons is a service of Thomas Jefferson University's Center for Teaching and Learning (CTL). The Commons is a showcase for Jefferson books and journals, peer-reviewed scholarly publications, unique historical collections from the University archives, and teaching tools. The Jefferson Digital Commons allows researchers and interested readers anywhere in the world to learn about and keep up to date with Jefferson scholarship. This article has been accepted for inclusion in Department of Pathology, Anatomy, and Cell Biology Faculty Papers by an authorized administrator of the Jefferson Digital Commons. For more information, please contact: JeffersonDigitalCommons@jefferson.edu. 
Published in final edited form as:

Neurotoxicology. 2015 May ; 48: 217-222. doi:10.1016/j.neuro.2015.04.004.

\title{
Effects of Chronic Manganese Exposure on Attention and Working Memory in Non-Human Primates
}

\author{
J.S. Schneider ${ }^{1}$, C. Williams ${ }^{1}$, M. Ault ${ }^{1}$, and T.R. Guilarte ${ }^{2}$ \\ ${ }^{1}$ Dept. of Pathology, Anatomy and Cell Biology, Thomas Jefferson University, Philadelphia, PA \\ ${ }^{2}$ Dept. of Environmental Health Sciences, Mailman School of Public Health, Columbia University, \\ New York, NY
}

\begin{abstract}
Manganese (Mn) is essential for a variety of physiological processes, but at elevated levels, can be neurotoxic. While cognitive dysfunction has been recently appreciated to occur as a result of chronic Mn exposures, it is still unclear as to which cognitive domains are most susceptible to disruption by Mn exposure. We previously described early appearing Mn-induced changes in performance on a paired associate learning task in monkeys chronically exposed to $\mathrm{Mn}$ and suggested that performance of this task might be a sensitive tool for detecting cognitive dysfunction resulting from Mn exposure. As chronic Mn exposure has been suggested to be associated with attention, working memory and executive function deficits, the present study was conducted to assess the extent to which detrimental effects of chronic Mn exposure could be detected using tasks specifically designed to preferentially assess attention, working memory, and executive function. Six cynomolgus monkeys received Mn exposure over an approximate 12 month period and three served as control animals. All animals were trained to perform a selfordered spatial search (SOSS) task and a five choice serial reaction time (5-CSRT) task. Deficits in performance of the SOSS task began to appear by the fourth month of Mn exposure but only became consistently significantly impaired beginning at the ninth month of Mn exposure.

Performance on the 5-CSRT became significantly affected by the third month of Mn exposure. These data suggest that in addition to the paired associate learning task, cognitive processing speed (as measured by the 5-CSRT) may be a sensitive measure of Mn toxicity and that brain circuits involved in performance of the SOSS task may be somewhat less sensitive to disruption by chronic Mn exposure.
\end{abstract}

(C) 2015 Published by Elsevier Inc.

Please address correspondence to: Dr. J. S. Schneider, Dept. of Pathology, Anatomy and Cell Biology, Thomas Jefferson University, Philadelphia, PA 19107; phone: 215-503-03770; Fax: 215-923-3808; jay.schneider@jefferson.edu.

Conflict of Interest Statement:

The authors declare that there are no conflicts of interest.

Publisher's Disclaimer: This is a PDF file of an unedited manuscript that has been accepted for publication. As a service to our customers we are providing this early version of the manuscript. The manuscript will undergo copyediting, typesetting, and review of the resulting proof before it is published in its final citable form. Please note that during the production process errors may be discovered which could affect the content, and all legal disclaimers that apply to the journal pertain. 


\section{Keywords}

Manganese; cognition; nonhuman primates

\section{Introduction}

Manganese (Mn) is an essential trace metal nutrient that is required for a variety of enzymatic processes in the brain and is important to maintain normal cellular functions (Hurley and Keen, 1987). However, excess Mn can be neurotoxic (Greger, 1998) and depending on the amount and duration of exposure, can lead to a variety of neurological problems. For example, high acute exposures or long-term exposure to high concentrations of Mn have been associated with a variety of motor function deficits including dystonia, pyramidal signs, and signs of parkinsonism (Gibley et al., 2001; Hathaway et al., 1996) while workers with chronic low level occupational exposure to Mn can also develop a motor syndrome with a clinical phenotype that substantially overlaps with that of Parkinson's disease (Racette et al., 2012Racette, 2014). While the effects of Mn exposure on motor dysfunction have been known for some time, it is only more recently that cognitive dysfunction has been appreciated to occur as a result of chronic exposure to lower levels of Mn than those needed to produce parkinsonism (Bowler et al., 2007a, Laohaudomchok et al., 2011). Dose-related cognitive deficits have now been consistently reported in human studies (Bowler et al., 2007b; Ellingsen et al., 2008).

We previously described subtle deficits in spatial and non-spatial working memory as well as subtle fine motor deficits in non-human primates exposed to low levels of Mn, with exposures lasting 227-272 days (Schneider et al., 2006; Schneider et al., 2009). At the lowest level of Mn exposure, subtle neuropsychological changes were evident on a spatial variable delayed response task (Schneider, et al., 2006) while at a higher exposure level, in the range of levels reported for human environmental, medical or occupational exposures, significant deficits on performance of a non-spatial working memory task (delayed matching-to-sample) appeared relatively early and remained for the duration of the study while performance deficits on the variable delayed response task were minimal and more variable from animal to animal (Schneider, et al., 2009).

The variable delayed response task, in which the subject has to simply remember the location of a stimulus during a variable delay period, may better reflect short-term memory processes than more executive working memory processes that involve simultaneous storage and processing of information (Baddeley, 1986). Accurate delayed response performance requires that the animal pay attention to the cue and possible reward location and remember that information for a short period of time. Variable performance on this task as observed previously could have been due to different effects of Mn exposure on attention, short-term memory processes or both in different monkeys. In contrast, a self-ordered spatial search (SOSS) task is a spatial working memory task with minimal attentional demands and requires monitoring of self-generated choices with performance of the task entirely dependent on memory of the visual stimuli, their spatial locations, and previous responses (i.e., both storage and processing or updating of information). 
As chronic Mn exposure has been suggested to be associated with attention, working memory and executive function deficits, the present study was conducted to assess the extent to which detrimental effects of chronic Mn exposure, at a level previously shown to affect non-spatial working memory (Schneider, et al., 2009), could be detected using tasks specifically designed to preferentially assess attention, working memory, and executive function. We used a five choice serial reaction time (5-CSRT) task to assess the ability to maintain an attentional focus with no dependence on working memory (i.e. each successive trial on the 5-CSRT has no relation to a previous trial and does not require holding and utilizing prior information on which to base a decision concerning new information). We also used a SOSS task to assess spatial working memory i.e. the ability to retain spatial information and to manipulate remembered items to discriminate information in a trial from information presented earlier in the testing: the self-ordered component also assesses heuristic (experience-based) strategy.

\section{Material and methods}

\subsection{Animals}

Nine adult male $M$. fascicularis macaques, 5-6 years old at the start of the study, were used; six received Mn exposure and three served as control animals that were treated exactly the same as the Mn-exposed animals but received vehicle injections. Animals were fed standard lab chow (LabDiet @5045, Animal Specialties and Provisions, Quakertown, PA, USA) supplemented with fruits or vegetables and water was available ad libitum in the home cage. Animals were food restricted in order to achieve training and stable responding on multiple tasks and restriction parameters and body weights were monitored regularly to ensure maintenance of good body condition scores. All animal studies were reviewed and approved by the Animal Care and Use Committee at Thomas Jefferson University and complied with the National Institutes of Health Guide for the Care and Use of Laboratory Animals.

\subsection{Behavioral training and testing}

Animals were adapted to sitting in a primate chair and trained to perform cognitive tasks while sitting in front of a automated test panel attached to the front wall of a soundattenuating, dimly lit, well-ventilated enclosure. Cognitive testing was achieved using the non-human primate Cambridge Neuropsychological Test Automated Battery (CANTAB) and the CANTAB Intellistation with pellet reward (Lafayette Neuroscience, Lafayette, IN, USA).

\subsection{Self-Ordered Spatial Search (SOSS) Task}

The SOSS task requires animals to touch identical squares located in different spatial locations in a self-ordered sequence without returning to a previously touched square. (see (Decamp et al., 2011) (Weed et al., 1999) (Zeamer et al., 2012)). The task had three levels of difficulty. At the simplest level, two blue boxes appear randomly on the screen in 16 possible locations and in no obvious pattern. For successful completion of the task, subjects must remember the location of each box and select (touch) all boxes without revisiting a box once it had been touched. After a touch, the screen blanks for $2 \mathrm{~s}$ and then the boxes reappear in the same locations as before. The animal needs to remember which box it 
previously touched and now touches the other one. If the animal touches the box that previously was not touched, it receives a reward; if it touches the same box it previously touched, no reward is given and the boxes disappear from the screen for a 20-s time-out period. If the animal touches all of the boxes in a sequence without a repetition, the trial is labeled 'correct'. Once a stable level of performance is achieved at this first and easiest level of the task, the next level of the task in which three squares are used, is introduced to the animal. Again, after a stable level of performance is achieved at the three-square level of difficulty, the next level of the task, in which four squares are used, is introduced. Training continued until performance stabilized. A testing session then consisted of 40 trials grouped into blocks by trial type: 2 boxes, 3 boxes, or 4 boxes. Accuracy scores (percent correct responses) were calculated for each trial type by dividing the number of correctly completed trials by the number of trials in which there was at least one response.

\subsection{Five Choice Serial Reaction Time (5-CSRT) Task}

The 5-choice serial reaction time (5-CSRT) task is a widely used test to measure multiple aspects of cognition including attention, impulsivity and perseveration (Auclair et al., 2009) (Higgins and Breysse, 2008). The test involves training animals to respond to a brief visual stimulus presented unpredictably in one of five locations on a touch sensitive screen. On this version of the test, the animal depresses a bar for $2 \mathrm{sec}$ and is presented with a set of five empty target stimuli (five empty circles) on the screen. One of the five circles turns yellow 0.5 to $1 \mathrm{sec}$ after the circles appear on the screen. Once a circle turns yellow, the animal has to touch it as quickly as possible. A touch of the filled circle within the allotted time period ( $5 \mathrm{sec}$. max) is scored as correct and reinforced. The number of correct responses, reaction time, movement time, early bar release errors are recorded. Each test session consisted of 100 trials.

\subsection{Mn Exposure}

Once animals achieved a stable baseline performance on all measures, they were transported to Johns Hopkins University for in vivo imaging studies (and received additional imaging studies throughout the study, results to be reported elsewhere). After return from the baseline imaging study, some animals underwent a surgical procedure for placement of an indwelling jugular catheter attached to a titanium vascular access port as described previously (Schneider et al., 2013). In these animals, Mn (or saline in control animals) was infused at a rate of approx. $0.5 \mathrm{ml} / \mathrm{min}$. followed by a flush of approx. $3.0-5.0 \mathrm{ml}$ of sterile saline and hep/dex locking solution (Schneider, et al., 2013). In order to minimize risk of injuries to staff and animals, the port was accessed while the animals were seated in the chair and while under light gas sedation (isofluorane $4 \%$ to induce, $2 \%$ to maintain, oxygen $1 \%$ ). Mn was administered as $\mathrm{MnSO}_{4}$ monohydrate (Sigma-Aldrich, St. Louis, Mo., USA; $15 \mathrm{mg} / \mathrm{kg} /$ week for 5 weeks and then $20 \mathrm{mg} / \mathrm{kg} /$ week for the remainder of the study period: in which the total dose per week was divided and given at two different times/week. Manganese sulfate was prepared fresh for each injection ( $50 \mathrm{mg} / \mathrm{ml}$ in sterile saline), $\mathrm{pH}$ adjusted to 7.0 , filtered, and warmed to $37{ }^{\circ} \mathrm{C}$ prior to use. Since the ports ultimately failed in most of the animals, as reported previously (Schneider, Williams, 2013), Mn or vehicle was administered intravenously by slow infusion through the saphenous vein, under the same anesthesia conditions used initially for port access. 


\subsection{Data Analysis}

Means and standard deviations were calculated for cognitive outcome measures at baseline (i.e., 3-4 weeks prior to the first Mn exposure) and at approximately 1 month intervals after the first Mn exposure. One-way analysis of variance followed by post hoc comparisons using Newman-Keuls test was used to analyze baseline performance. Task performance prior to and following Mn exposure was compared by repeated measures analysis of variance for each measure with appropriate post hoc comparisons (Dunnett's post hoc $t$ test) made to assess changes between baseline and each post Mn observation period. Additional one-way analysis of variance with post hoc Newman-Keuls test compared performance between conditions (i.e., vehicle vs. Mn-exposed). Statistical significance was defined at $\mathrm{p}<0.05$.

\section{Results}

\subsection{Manganese administration}

The mean \pm s.e.m. cumulative amount of $\mathrm{Mn}$ administered over an approximate 52 week period was $389.0 \pm 6.6 \mathrm{mg} \mathrm{Mn} / \mathrm{kg}$ body weight. Mean baseline blood Mn levels in the control group were $11.3 \pm 2.8 \mu \mathrm{g} / \mathrm{L}$ and $8.7 \pm 2.4 \mu \mathrm{g} / \mathrm{L}$ in the Mn exposure group. At the end of the study period, blood Mn levels in the control animals were $7.0 \pm 1.5 \mu \mathrm{g} / \mathrm{L}$ and $108.4 \pm$ $9.3 \mu \mathrm{g} / \mathrm{L}$ in Mn-exposed animals.

\subsection{Effects of Chronic Mn Exposure on Self-Ordered Spatial Search (SOSS) Task Performance}

On the SOSS task, in the baseline condition, the animals in the Mn exposure group easily completed the easiest level of the task ( 2 squares: $97.8 \pm 0.9$ percent correct) but had more difficulty performing the 3 squares and 4 squares levels of the task $(81.3 \pm 2.2$ and $60.1 \pm$ 4.1 percent correct, respectively). Analysis of variance showed a statistically significant effect of task difficulty on task performance at baseline $\left(F_{(2,51)}=47.85, p<0.0001\right)$. Posthoc comparisons showed significant differences between performance at 2 squares and 3 squares ( $p<0.001)$, between 3 squares and 4 squares ( $<<0.0001)$, and between performance at 2 squares and 4 squares $(\mathrm{p}<0.0001)$.

Mn exposure had significant effects on SOSS task performance (Figure 1). At the easiest level of the task (2 squares), there was no significant change in performance over the $\mathrm{Mn}$ exposure period $\left(\mathrm{F}_{(12,17)}=1.48, \mathrm{p}=0.1336\right)$. There was a significant effect of time of $\mathrm{Mn}$ exposure on performance of 3 squares trials $\left(\mathrm{F}_{(12,17)}=1.83, \mathrm{p}<0.05\right)$ with significant decreases in performance at months 6,8 and $9 \mathrm{Mn}$ exposure $(\mathrm{p}<0.05$ for each vs. baseline; Figure 1A). There was also a significant effect of time of Mn exposure on performance of 4 squares trials $\left(\mathrm{F}_{(12,17)}=3.91, \mathrm{p}<0.0001\right)$. At this most difficult task level, performance was affected by the third month of Mn exposure and became consistently significantly impaired from the seventh month of Mn exposure (Figure 1A). In three animals that continued to receive Mn exposure out to 18 months, there was no significant difference between SOSS performance after 12 months of Mn exposure and SOSS performance after 18 months of Mn exposure (data not shown). 


\subsection{Self-Ordered Spatial Search (SOSS) Task Performance of Control Animals}

In the baseline condition, the control animals also easily performed the 2 squares level of the task and had increasing difficulty performing the next two task levels $(96.7 \pm 1.7$ percent correct, $68.9 \pm 3.7$ percent correct, $30.0 \pm 4.0$ percent correct 2 square, 3 square and 4 square levels of the task, respectively). There was also a significant effect of task difficulty on performance at baseline $\left(\mathrm{F}_{(2,24)}=103.6, \mathrm{p}<0.0001\right)$. Posthoc comparisons showed significant differences between performance at 2 squares and 3 squares $(p<0.0001)$, between 3 squares and 4 squares $(\mathrm{p}<0.0001)$, and between performance at 2 squares and 4 squares ( $\mathrm{p}<0.0001$ ) (Figure 1B). Similar to the Mn-treated animals, there were no significant effect of time (saline injections) on performance of the easiest level of the task, compared to baseline performance $\left(\left(\mathrm{F}_{(12,8)}=1.95, \mathrm{p}=0.163\right)\right.$; Figure 1B). There was a significant effect of time of saline administration on performance of 3 squares trials $\left(\mathrm{F}_{(12,8)}\right.$ $=3.73, \mathrm{p}=0.016)$ and 4 square trials $\left(\mathrm{F}_{(12,8)}=7.18, \mathrm{p}=0.0003\right)$ but in the opposite direction of that observed in Mn-exposed animals. That is, in control animals, performance tended to improve over time while in Mn-exposed animals, performance tended to deteriorate over time (compare Figures 1A and 1B).

\subsection{Effects of Chronic Mn Exposure on 5 Choice Serial Reaction Time (5-CSRT) Task Performance}

The 5-CSRT task allows examination of sustained and divided attention abilities (measured by correct detection of a brief visual stimulus presented across one of five locations as well as impulsivity or the inability to inhibit a response in the anticipation of reward (measured by premature responding (early bar release) before the onset of the stimulus) and perseverative responding indicative of compulsive behaviour (i.e. additional responses performed after a correct one but before collection of the reward). Additionally, reaction (response) time (time between appearance of the stimulus on the screen and release of the bar and a measure of speed of processing) and movement time (time between release of bar and touch of the screen, a measure of motor function) were recorded.

In the $\mathrm{Mn}$ exposure group, there was a significant effect of time on the number of correct responses $\left(\mathrm{F}_{(12,17)}=3.36, \mathrm{p}=0.0002\right)$ : posthoc comparisons showed a significant difference between baseline performance and Mn exposure only at the 12 month time period ( $\mathrm{p}<$ 0.001). There was no significant effect of time on early bar release errors $\left(\mathrm{F}_{(12,17)}=1.77, \mathrm{p}\right.$ $=0.149)$. There was a significant effect of time on reaction (response) time $\left(\mathrm{F}_{(12,17)}=4.83\right.$, $\mathrm{p}<0.0001)$ as well as on movement time $\left(\mathrm{F}_{(12,17)}=2.47, \mathrm{p}=0.005\right)$. Posthoc comparisons showed a significant difference in reaction times between baseline performance and $\mathrm{Mn}$ exposure beginning at the $3^{\text {rd }}$ month of Mn exposure and remaining for the rest of the study period (Figure 2A). Reaction times got progressively longer over the course of the study. Although there was a main effect of time in the study on movement times, posthoc comparisons showed that movement times were significantly different from baseline only at the 12 month period (Figure 2A). In the three animals that continued to receive Mn exposure out to 18 months, there was no significant difference in 5-CSRT task performance after 12 months of Mn exposure compared to performance after 18 months of Mn exposure (data not shown). 


\subsection{5-Choice Serial Reaction Time (5-CSRT) Task Performance of Control Animals}

In the control animals, there was no significant effect of time on the number of correct responses $\left(\mathrm{F}_{(12,8)}=1.37, \mathrm{p}=0.1919\right)$, the number of early bar release errors $\left(\mathrm{F}_{(12,8)}=1.37\right.$, $\mathrm{p}=0.1919)$, reaction time $\left(\mathrm{F}_{(12,8)}=1.49, \mathrm{p}=0.1402\right)$, or movement time $\left(\mathrm{F}_{(12,8)}=0.61, \mathrm{p}=\right.$ 0.8294). Performance on this task was very stable over time in the control group (Figure 2B).

\section{Discussion}

The current findings show that performance of non-human primates on a self-ordered spatial search working memory task is impaired with chronic Mn exposure, with deficits evident at the most difficult level of the task and no effects of Mn exposure on the easiest level of the task. In contrast, control animals that received vehicle administration according to the same dosing schedule as Mn administration, either showed no change over time or improvement in performance, compared to their baseline level of task performance. These data are consistent with a previous report from this lab that described deficits on the performance of a visuospatial associative learning task on which performance at the easiest level of the task was unaffected by Mn exposure but more difficult levels of the task were significantly affected by Mn exposure, suggesting that the effects of Mn on performance on these types of tasks is associated with trial difficulty and that $\mathrm{Mn}$ interferes with task performance in a memory-load specific manner (Schneider, et al., 2013). As all trials on the SOSS task require the same motor response, the effects currently observed cannot be attributed to a $\mathrm{Mn}$-induced impairment in motor function that could have interfered with task performance. The performance deficit observed on the SOSS task appeared later in the course of Mn exposure than did deficits on the visuospatial paired associate learning (PAL) task as previously described by us (Schneider, et al., 2013). SOSS performance deficits began to appear by the fourth month of Mn exposure and became consistently significantly impaired beginning at the ninth month of Mn exposure. In contrast, deficits on the PAL task appeared within the first 2 to 3 months of Mn exposure and remained significantly impaired for the remainder of the study (Schneider, et al., 2013). This suggests that the brain circuits involved in performance of the PAL task may be more sensitive to the disrupting effects of Mn exposure than are the circuits involved in performance of the SOSS task. Previous studies examining the effects of task difficulty during performance of a paired associate learning task in humans reported activation patterns in a distributed frontoparietal network and with increasing task difficulty, changes in activation in occipitoparietal regions (Gould et al., 2005, Gould et al., 2003). In humans performing a task similar to the SOSS task used here, brain activation was observed primarily in dorsolateral and ventrolateral frontal cortices with tasks of increasing difficulty (Owen et al., 1996). It is possible that the networks involved in performance of PAL tasks are somewhat different from those involved in performance of the SOSS task and are more sensitive to disruption by Mn exposure.

Using a 5-CSRT task we examined attention abilities (measured by correct detection of a brief visual stimulus presented in one of five possible locations), impulsivity (measured by premature responding) and reaction (response) time (measure of processing speed) and movement time (measure of motor function). Mn-exposed animals showed some evidence 
of impaired attention. Evidence of a processing speed problem became evident earlier, with increased response times evident by the third month of Mn exposure. We found no evidence of impulsive responding on this task. Control animals that received vehicle administration according to the same schedule as Mn administration showed no change in 5-CSRT performance throughout the study. The effects on response time observed in Mn-exposed monkeys could reflect dysfunction of the dopamine (DA) system in these animals. We have previously reported that in positron emission tomography (PET) studies of monkeys chronically exposed to moderate levels of Mn there is no loss of DA terminals per se (Guilarte et al., 2008, Guilarte et al., 2006). However, there is a highly significant effect of Mn on DA terminal dysfunction, evidenced by a marked ( $60 \%$ from baseline) and progressive decrease of in vivo dopamine release in the striatum of Mn-exposed animals (Guilarte, et al., 2008, Guilarte, et al., 2006). In rats treated with drugs that cause DA release (ex., amphetamine), accuracy is improved on a 5-CSRT task and faster reaction times are recorded. Drugs that antagonize DA receptors (ex., raclopride) impair 5-CSRT accuracy and slow responding (Higgins and Breysse, 2008). Thus, it is possible that a Mn-induced deficiency in DA release may underlie the prolonged response times observed in the current study and may also contribute to the decreased accuracy observed at the at the end of the study when the effect of Mn on DA release may be greater.

The blood Mn levels reported here are consistent with the upper range of environmental, medical and occupational exposures (ex., (Takser et al., 2003, Santos-Burgoa et al., 2001)) and consistent with those previously reported by us in prior nonhuman primate studies (Schneider, et al., 2013). However, blood Mn levels may not necessarily accurately reflect Mn concentration in the brain, due to the ways in which absorbed Mn is sequestered and transported (Zheng et al., 2011). A number of studies have shown that blood Mn may not be the best biomarker of Mn exposure or toxicity, especially under conditions of chronic exposure (Laohaudomchok, et al., 2011, Zheng, et al., 2011). Blood Mn levels may reflect exposure over a short and recent period of time (hours to days) but may not provide important information on the relationship between exposure and a biological effect in a target tissue like brain for chronic exposures (Laohaudomchok, et al., 2011, Zheng, et al., 2011).

In conclusion, the current study describes deficits in performance of a self-ordered spatial search task and modest attentional deficits as detected using a 5 choice serial reaction time task, in monkeys chronically exposed to $\mathrm{Mn}$. These data add to the literature on the detrimental effects of chronic Mn exposure on cognition and, together with ongoing in vivo and ex vivo characterization of the functional and neurochemical integrity of the brain, will provided further understanding of the pathophysiology of chronic Mn exposure.

\section{Acknowledgments}

This work was funded by NIH grant R01 ES010975. 


\section{References}

Auclair AL, Besnard J, Newman-Tancredi A, Depoortere R. The five choice serial reaction time task: comparison between Sprague-Dawley and Long-Evans rats on acquisition of task, and sensitivity to phencyclidine. Pharmacol Biochem Behav. 2009; 92:363-9. [PubMed: 19353758]

Baddeley, AD. Working memory. New York: Oxford University Press; 1986.

Bowler RM, Nakagawa S, Drezgic M, Roels HA, Park RM, Diamond E, et al. Sequelae of fume exposure in confined space welding: a neurological and neuropsychological case series. Neurotoxicology. 2007a; 28:298-311. [PubMed: 17169432]

Bowler RM, Roels HA, Nakagawa S, Drezgic M, Diamond E, Park R, et al. Dose-effect relationships between manganese exposure and neurological, neuropsychological and pulmonary function in confined space bridge welders. Occup Environ Med. 2007b; 64:167-77. [PubMed: 17018581]

Decamp E, Clark K, Schneider JS. Effects of the alpha-2 adrenoceptor agonist guanfacine on attention and working memory in aged non-human primates. Eur J Neurosci. 2011; 34:1018-22. [PubMed: 21883531]

Ellingsen DG, Konstantinov R, Bast-Pettersen R, Merkurjeva L, Chashchin M, Thomassen Y, et al. A neurobehavioral study of current and former welders exposed to manganese. Neurotoxicology. 2008; 29:48-59. [PubMed: 17942157]

Gibley, RL.; Sullivan, JB, Jr. Manganese. In: Sullivan, JB.; JGRK, editors. Clinical Environmental Health and Toxic Exposures. Philadelphia: Lippincott; 2001. p. 930-7.

Gould RL, Brown RG, Owen AM, Bullmore ET, Williams SC, Howard RJ. Functional neuroanatomy of successful paired associate learning in Alzheimer's disease. Am J Psychiatry. 2005; 162:204960. [PubMed: 16263844]

Gould RL, Brown RG, Owen AM, ffytche DH, Howard RJ. fMRI BOLD response to increasing task difficulty during successful paired associates learning. Neuroimage. 2003; 20:1006-19. [PubMed: 14568470]

Greger JL. Dietary standards for manganese: overlap between nutritional and toxicological studies. J Nutr. 1998; 128:368S-71S. [PubMed: 9478027]

Guilarte TR, Burton NC, McGlothan JL, Verina T, Zhou Y, Alexander M, et al. Impairment of nigrostriatal dopamine neurotransmission by manganese is mediated by pre-synaptic mechanism(s): implications to manganese-induced parkinsonism. J Neurochem. 2008; 107:123647. [PubMed: 18808452]

Guilarte TR, McGlothan JL, Degaonkar M, Chen MK, Barker PB, Syversen T, et al. Evidence for cortical dysfunction and widespread manganese accumulation in the nonhuman primate brain following chronic manganese exposure: a 1H-MRS and MRI study. Toxicol Sci. 2006; 94:351-8. [PubMed: 16968886]

Hathaway, GJ.; Proctor, NH.; Hughes, JP. Proctor and hughes' chemical hazards of the workplace. 4. New York: Van Nostrand Reinhold; 1996.

Higgins GA, Breysse N. Rodent model of attention: the 5-choice serial reaction time task. Curr Protoc Pharmacol. 2008; Chapter 5(Unit5):49. [PubMed: 22294229]

Hurley, LS.; CLK. Manganese. In: Mertz, W., editor. Trace Elements in Human and Animal Nutrition. 5. San Diego: Academic Press; 1987. p. 185-223.

Laohaudomchok W, Lin X, Herrick RF, Fang SC, Cavallari JM, Shrairman R, et al. Neuropsychological effects of low-level manganese exposure in welders. Neurotoxicology. 2011; 32:171-9. [PubMed: 21192973]

Owen AM, Evans AC, Petrides M. Evidence for a two-stage model of spatial working memory processing within the lateral frontal cortex: a positron emission tomography study. Cereb Cortex. 1996; 6:31-8. [PubMed: 8670636]

Racette BA. Manganism in the 21st century: the Hanninen lecture. Neurotoxicology. 2014; 45:201-7. [PubMed: 24148923]

Racette BA, Aschner M, Guilarte TR, Dydak U, Criswell SR, Zheng W. Pathophysiology of manganese-associated neurotoxicity. Neurotoxicology. 2012; 33:881-6. [PubMed: 22202748]

Santos-Burgoa C, Rios C, Mercado LA, Arechiga-Serrano R, Cano-Valle J, Eden-Wynter RA, Texcalac-Sangrador JP, Rodriguez-Agudelo Y, Montes S. Exposure tomanganese: health effects 
on the general population, a pilot study in central Mexico. Environ Res. 2001; 85:90-104. [PubMed: 11161659]

Schneider JS, Decamp E, Clark K, Bouquio C, Syversen T, Guilarte TR. Effects of chronic manganese exposure on working memory in non-human primates. Brain Res. 2009; 1258:86-95. [PubMed: 19133246]

Schneider JS, Decamp E, Koser AJ, Fritz S, Gonczi H, Syversen T, et al. Effects of chronic manganese exposure on cognitive and motor functioning in non-human primates. Brain Res. 2006; 1118:22231. [PubMed: 16978592]

Schneider JS, Williams C, Ault M, Guilarte TR. Chronic manganese exposure impairs visuospatial associative learning in non-human primates. Toxicol Lett. 2013; 221:146-51. [PubMed: 23778301]

Takser L, Mergler D, Hellier G, Sahuquillo J, Huel G. Manganese, monoamine metabolite levels at birth, and child psychomotor development. Neurotoxicology. 2003; 24:667-74. [PubMed: 12900080]

Weed MR, Taffe MA, Polis I, Roberts AC, Robbins TW, Koob GF, et al. Performance norms for a rhesus monkey neuropsychological testing battery: acquisition and long-term performance. Brain Res Cogn Brain Res. 1999; 8:185-201. [PubMed: 10556598]

Zeamer A, Clark K, Bouquio C, Decamp E, Schneider JS. Impaired spatial working memory learning and performance in normal aged rhesus monkeys. Behav Brain Res. 2012; 232:287-93. [PubMed: 22546522]

Zheng W, Fu SX, Dydak U, Cowan DM. Biomarkers of manganese intoxication. Neurotoxicology. 2011; 32:1-8. [PubMed: 20946915] 


\section{Highlights}

- Chronic Mn exposure may result in cognitive dysfunction

- Animals received Mn exposure over an approximate 12 month period

- Animals developed a working memory deficit after 7 months of Mn exposure

- Animals developed an early processing speed deficit. 
A.

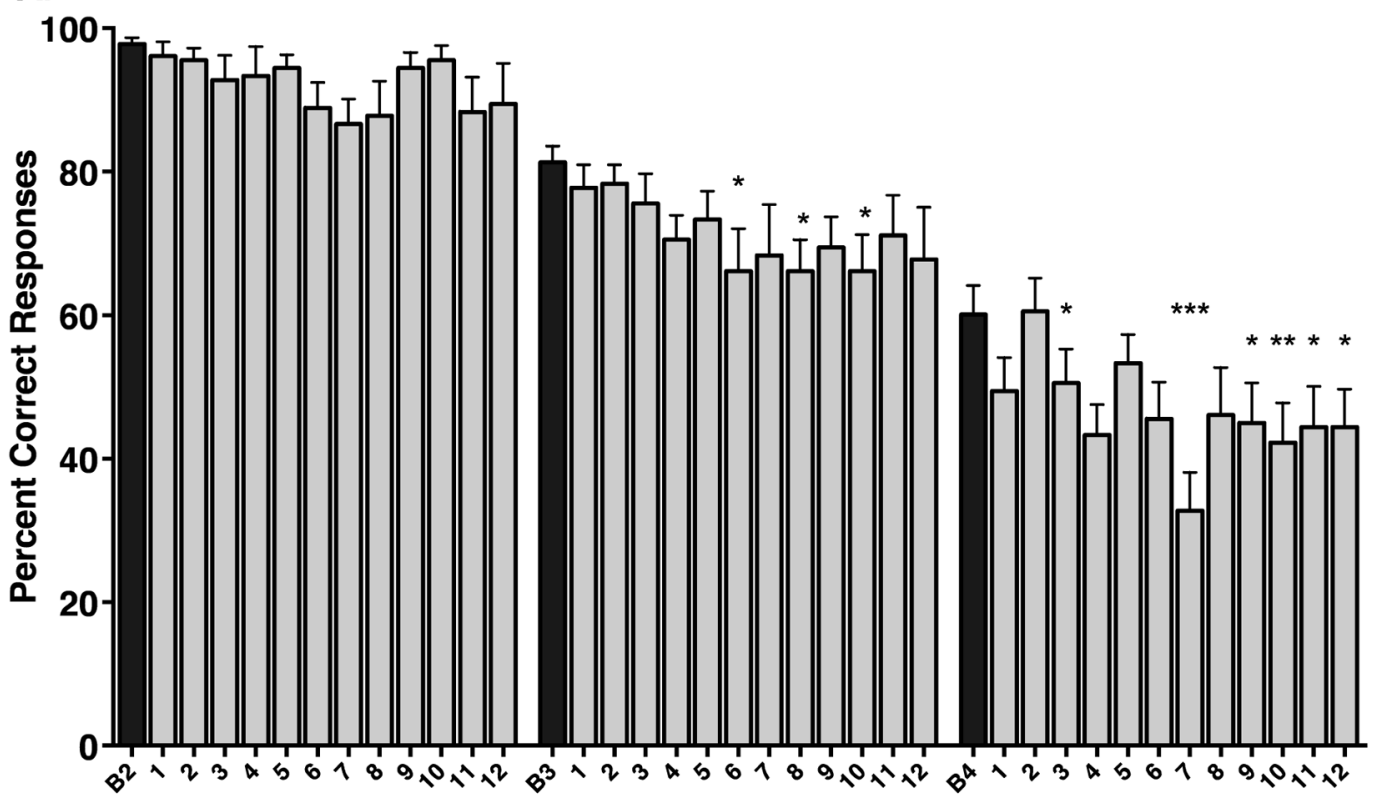

B.

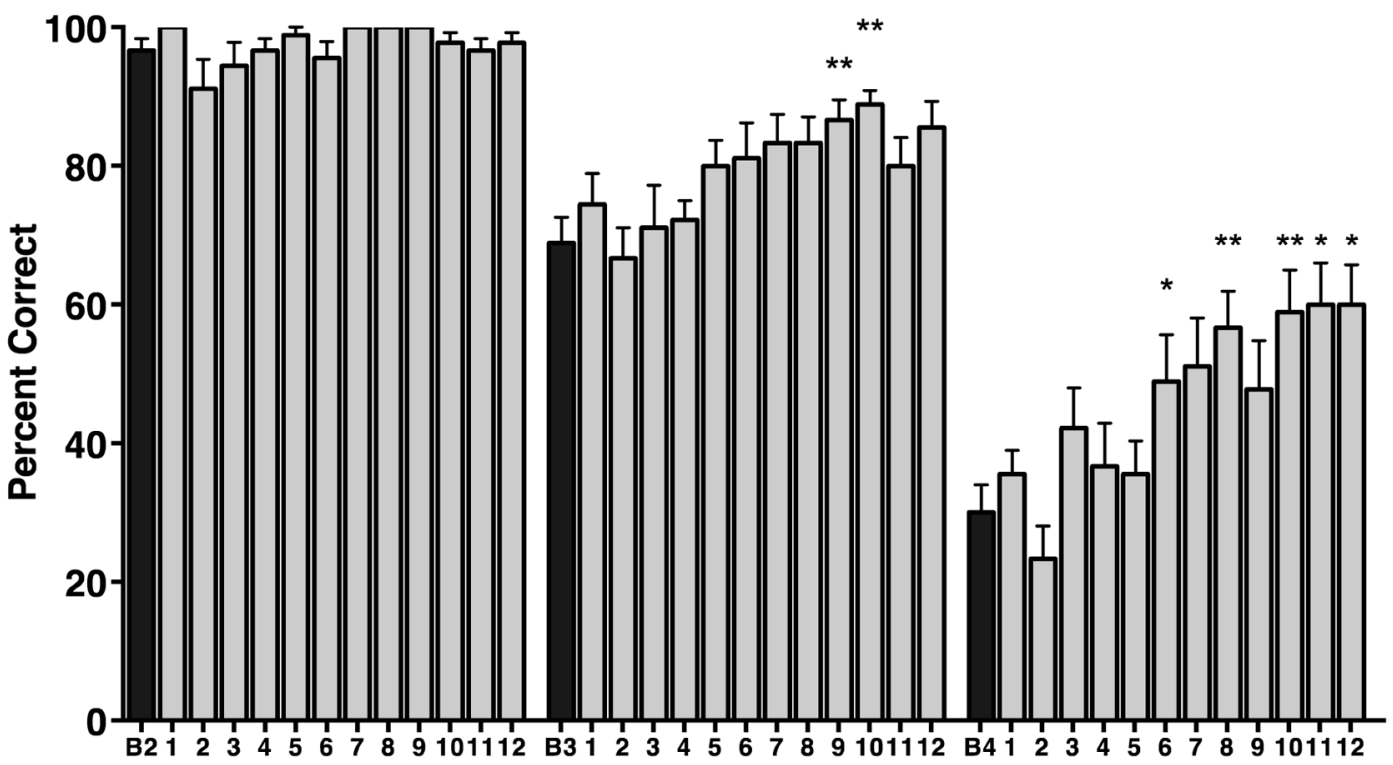

Figure 1.

Spatial working memory performance in Mn-exposed animals (A) and in control non-Mnexposed animals (B). A. Manganese exposure had no significant effect on the number of correct responses made on the easiest version of the task (2 Squares) but had significant detrimental effects on task performance beginning at the intermediate level of task difficulty (3 Squares) and at the most difficult level of the task (4 Squares). B. In comparison to Mnexposed animals, control animals to perform the task better over time, particularly at the intermediate (3 Squares) and difficult (4 Squares) levels of the task. Significant improvements in performance were seen on the 4 Squares level of the task from the $7^{\text {th }}$ 
through $12^{\text {th }}$ months of testing. Data are presented as means \pm SEMs; numbers on $x$-axis indicate months; $* p<0.05, * * p<0.01, * * * p<0.0001$ vs. respective baseline (B) performance). 

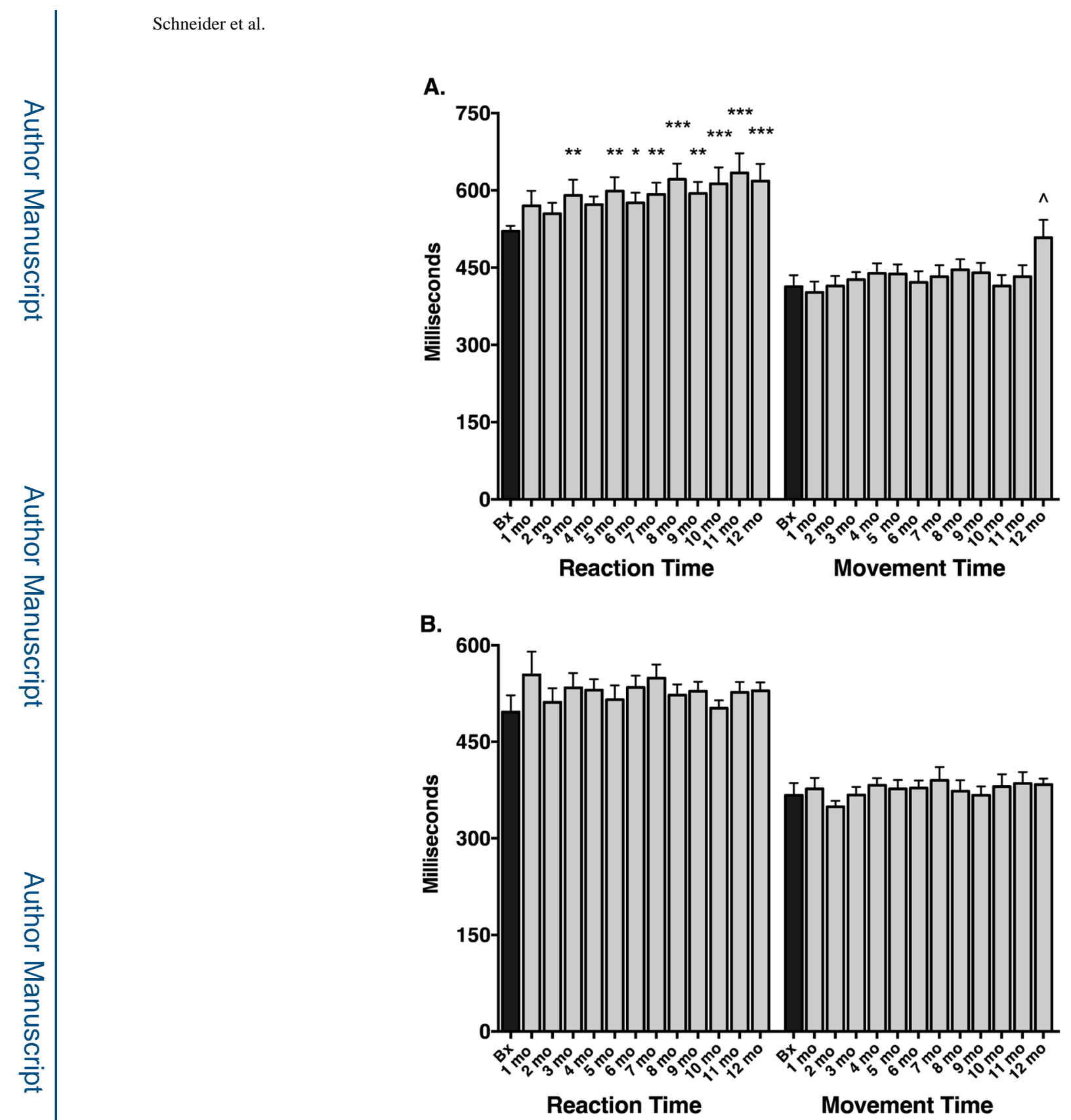

Figure 2.

Five choice serial reaction time performance in Mn-exposed animals (A) and in control nonMn-exposed animals (B). A. Manganese exposure had a significant effect on reaction times, with significantly increased reaction times appearing beginning around the $3^{\text {rd }}$ to $5^{\text {th }}$ months of Mn exposure. Movement times were generally unaffected except at the last timepoint and most of this effect was driven by a single animal. B. In comparison to Mn-exposed animals, control animals performed the task with remarkable stability over the course of the study period. No changes over time were observed in either reaction or movement times in the control animals. Data are presented as means \pm SEMs; numbers on $\mathrm{x}$-axis indicate months; ${ }^{*} \mathrm{p}<0.05,{ }^{* *} \mathrm{p}<0.01, * * * \mathrm{p}<0.0001, \wedge \mathrm{p}<0.001$ vs. respective baseline (B) performance). 